\title{
O papel do conselho de escola nas Escolas Municipais de Ensino Fundamental (EMEF) em Vitória, no Estado do Espírito Santo, Brasil
}

The role of the school council in Municipal Elementary Schools (EMEF) in Vitória, in State of Espírito Santo, Brazil

El papel del consejo escolar en las Escuelas Primarias Municipales (EMEF) en Vitória, Estado de Espírito Santo, Brasil

Recebido: 21/12/2020 | Revisado: 23/12/2020 | Aceito: 27/12/2020 | Publicado: 02/01/2021

Marilene Coutinho de Souza Gonçalves

ORCID: https://orcid.org/0000-0003-3781-4262 Faculdade Novo Milênio, Brasil E-mail: marii1503@hotmail.com

Lilian Simone Godoy Fonseca

ORCID: https://orcid.org/0000-0002-8079-7405 Filiação: Uni. Fed. dos Vales do Jequitinhonha e Mucuri, Brasil E-mail: godoylilian2@gmail.com

Marcio Coutinho de Souza

ORCID: https://orcid.org/0000-0002-4238-1572 Universidade Federal dos Vales do Jequitinhonha e Mucuri, Brasil E-mail: marcio.souza@ufvjm.edu.br

\begin{abstract}
Resumo
O artigo objetiva analisar um dos mecanismos da Gestão Democrática - o Conselho de Escola, sob a percepção desse órgão colegiado. Aplica metodologia qualitativa com entrevistas semiestruturadas aos titulares dos Conselhos de Escola em quatro Escolas Municipais de Ensino Fundamental, utiliza a análise de conteúdo de Bardin. Se destacam as unidades de registro: participação, fortalecimento, compartilhada, conversa, críticas, entre outras. A estatística simples demonstrou a relação direta de 1-Conselho, 2-Participar e 3-Gestão Democrática, totalizando o percentual de 40,41\% das frequências, sendo o Conselho de Escola o órgão colegiado que deve gerir a escola.
\end{abstract}

Palavras-chave: Gestão democrática; Conselho de escola; Participação.

\begin{abstract}
The article aims to analyze one of the mechanisms of Democratic Management - the School Council, under the perception of this collegiate body. Applies a qualitative methodology with semi-structured interviews to the holders of the School Councils in four Municipal Schools of Elementary Education, using the content analysis of Bardin. Noteworthy are the registration units: participation, strengthening, sharing, conversation, criticism, among others. The simple statistic showed the direct relationship of 1-Council, 2-Participate and 3-Democratic Management, totaling the percentage of $40.41 \%$ of frequencies, and the School Board is the collegiate body that must manage the school.
\end{abstract}

Keywords: Democratic management; School council; Participation.

\section{Resumen}

El artículo tiene como objetivo analizar uno de los mecanismos de Gestión Democrática - el Consejo Escolar, bajo la percepción de este órgano colegiado. Aplica metodología cualitativa con entrevistas semiestructuradas a los responsables de los Consejos Escolares en cuatro Escuelas Municipales de Educación Primaria, utiliza el análisis de contenido de Bardin. Se destacan las unidades de registro: participación, fortalecimiento, compartido, conversación, crítica, entre otras. La estadística simple mostró la relación directa de 1-Consejo, 2-Participar y 3-Gestión democrática, totalizando el porcentaje del 40,41\% de las frecuencias, siendo el Consejo Escolar el órgano colegiado que debe gestionar la escuela.

Palabras clave: Gestión democrática; Consejo escolar; Participación.

\section{Introdução}

No Brasil, a Gestão Democrática no ambiente escolar passou a ser buscada no final da década de 1980, com a inserção na Constituição Federal de 1988 e a normatização na Lei de Diretrizes e Bases da Educação Nacional de 1996. Essas leis foram conquistadas pelos movimentos sociais organizados e pelo envolvimento de educadores, no cenário de luta política 
por uma escola pública democrática e com qualidade.

No decorrer desses anos, a busca tem sido por uma gestão colegiada, em que os seus segmentos possam participar ativamente da construção coletiva desse espaço público, eliminando as barreiras do autoritarismo, clientelismo e favoritismo. Nessa perspectiva, Paro (2000), destaca alguns mecanismos da gestão democrática no interior da escola: o Conselho de Escola, a Eleição de Diretor e a construção coletiva do Projeto Político Pedagógico.

Destarte esse artigo tem o objetivo de analisar um dos mecanismos da Gestão Democrática - o Conselho de Escola, sob a percepção desse órgão colegiado. Nesse contexto surge o seguinte problema central da pesquisa: Qual é o papel do Conselho de Escola na Gestão Democrática na percepção do órgão colegiado?

No município pesquisado a organização do Conselho de Escola como unidade executora dos recursos financeiros ocorreu a partir da Lei de $\mathrm{n}^{\circ}$ 6.794, instituída no dia 29 do mês de novembro de 2006. Em um universo de 52 (cinquenta e duas) EMEFs, o lócus de pesquisa são quatro Escolas Municipais de Ensino Fundamental (EMEFs) localizadas no município de Vitória, no Estado do Espírito Santo.

O Conselho de Escola, segundo a Lei anteriormente citada, é constituído por: diretor da Unidade Escolar (representante nato); representantes do grupo do Magistério (dois titulares e dois suplentes); representantes dos servidores (dois titulares e dois suplentes); representantes de pais ou responsável legal pelo aluno (dois titulares e dois suplentes); representantes de alunos (dois titulares e dois suplentes) e o representante eleito pelas entidades de movimentos comunitários do bairro onde a EMEF está inserida (um titular e um suplente).

O Conselho de Escola deve ser escolhido por eleição direta de acordo com o segmento. Nesse contexto, se fazem necessárias as escutas dos sujeitos que ocupam a função de conselheiros, em um processo de eleição direta, como representantes de segmentos de pais, alunos, magistério, comunidade e servidores.

\section{O Conselho e o Contexto Escolar}

De acordo com Riscal (2010, p. 23), “o termo conselho, derivado do latim 'consilium', apresenta, desde os registros de documentação da antiga Roma, diferentes conotações, que vão do significado de aconselhamento à reunião para decisão de assuntos públicos".

Ainda de acordo Riscal (2010, p. 24), os conselhos são as mais antigas estruturas políticas, desde as primeiras civilizações da Antiguidade mesopotâmica "em geral, se tratava de conselhos de anciãos, sacerdotes ou de notáveis, cujo papel era aconselhar os soberanos em aspectos religiosos ou em momentos de crise, como guerras". Na Idade Média, os conselhos se expandiram por toda Europa, dirimindo assuntos de cunhos religiosos e políticos. Já as comunas, conselhos municipais, tornaram-se um importante mecanismo de independência das cidades ao término da Idade Média. Já na Idade Moderna, os reis absolutistas, mantinham um conselho privado, para elaborar estratégias políticas, militares e econômicas (Riscal, 2010).

De acordo com Ramos e Fernandes (2010), historicamente, quando se registram os primeiros conselhos eles se instituem a partir de grupos selecionados de sábios e anciãos, com intuito de ajudar o governo no controle do povo. No entanto, os conselhos que surgem no final do século XIX nascem no intuito de inserir o povo, de alguma maneira, no governo. São os conselhos de operários e os populares, propagado nas sociedades capitalistas, por grupos socialistas.

Enquanto na sociedade capitalista europeia os conselhos são instituídos visando a participação popular no século XIX, no Brasil ela se dará no século XX. Assim, “no Brasil, esses conselhos populares e de fábricas começaram a se desenvolver especialmente a partir dos anos de 1970, vinculados à luta de movimentos sociais, que passaram a se organizar contra o regime militar brasileiro - que chegou ao poder em 1964" (Ramos \& Fernandes, 2010, p. 47). A partir da década de 1970, deu-se no país uma clara divulgação e reconhecimento político do papel dos conselhos por parte de diferentes grupos (liberais e de esquerda), como instâncias importantes e indispensáveis para a constituição de uma sociedade democrática (Ramos \& 
Fernandes, 2010).

No contexto da redemocratização do país, na década de 1980, os movimentos associativos populares passaram a reclamar participação na gestão pública. $\mathrm{O}$ desejo de participação comunitária se inseriu nos debates da Constituinte, que geraram, posteriormente, a institucionalização dos conselhos gestores de políticas públicas no Brasil. Esses conselhos tem um caráter nitidamente de ação política e aliam o saber letrado com o saber popular, por meio da representação das categorias sociais de base. São muitas as formas de organização e as funções atribuídas a esses conselhos, mas sua origem radica sempre no desejo de participação e ação na formulação e na gestão das políticas públicas (Brasil, 2004, p. 19).

Para Sousa (2016), no que tange ao Conselho de Escola é importante diferenciar esse órgão e Unidade Executora. O Conselho de Escola é a instância colegiada constituída dos membros da escola, com atribuições de cunho pedagógico, administrativo e financeiro, enquanto a Unidade Executora:

[...] é uma sociedade civil, com personalidade jurídica de direito privado sem fins lucrativos, representativa das escolas públicas e integrada por membros da comunidade escolar, responsável pela formalização dos procedimentos necessários ao recebimento dos repasses de recursos financeiros destinados à escola, incluindo a execução e a prestação de contas desses recursos (Sousa, 2016, p. 27).

Na prática ocorre a continuidade da centralização normativa, enquanto os recursos financeiros, sua aplicação, a responsabilidade quanto ao investimento na escola e a prestação de contas, tornam-se responsabilidade do Conselho de Escola, como Unidade Executora. Isso aumenta a responsabilização da sociedade civil, quanto às melhorias da escola, pois, ela recebe os recursos diretos na escola e precisa ter competência técnica para administrá-lo, de acordo com a visão do Estado (Delgado, 2015). “A desconcentração passa a ser uma estratégia utilizada para desobrigar o Estado com relação à execução de políticas públicas, promovendo uma aparente democratização, mas mantendo centralizado o poder político” (Delgado, 2015, p. 42).

A partir do Art. 206 da Constituição Federal de 1988, as legislações concernentes à gestão da escola, basearem-se no princípio da Gestão Democrática, assim como, os programas e projetos envolvendo a educação pública. É nesse contexto, que entre os anos de 2002 e 2006 é criado o Programa de Fortalecimento dos Conselhos Escolares, criado pela Portaria Ministerial $n^{\circ}$ 2.896, de 16 do mês de setembro de 2004-MEC (Castro, 2016), que dentre outros objetivos visava "ampliar a participação das comunidades escolar e local na gestão administrativa, financeira e pedagógica das escolas públicas” (Brasil-MEC, 2004, p. $1)$.

Ainda, de acordo com o Ministério da Educação (Brasil, 2004) existe o perfil adequado de conselheiro para que ele possa exercer bem o seu papel. Diante disso, é preciso conhecer o conselho e o que significa representar um segmento, isso posto, ratifica a intencionalidade do Conselho de Escola ser um órgão de ação colegiada e seus membros não se auto representarem, mas, buscarem a escuta dos anseios do segmento no qual ele foi eleito para representar.

Outra característica importante do conselheiro é que ele tenha conhecimento do sistema de ensino no qual ele está inserido, suas legislações, programas e projetos. E, no espaço micro da escola, é imprescindível que ele conheça o projeto político pedagógico da EMEF, seu regimento, os recursos financeiros, a comunidade, os projetos, enfim, a história e o funcionamento da instituição. Isso requer do conselheiro uma participação efetiva.

Contudo, Paro (2000) destaca que já existe a dificuldade para que os pais tenham a iniciativa e o desejo em participar como candidatos, na eleição do Conselho de Escola e, mais ainda, "um dos principais fatores que impedem que o Conselho de Escola se transforme num instrumento de democratização das relações no interior da escola é a falta de ligação entre representantes e representados, especialmente no que se refere a pais e alunos" (Paro, 2000, p. 149).

As funções do Conselho de Escola são: deliberativas, consultivas, fiscais e mobilizadoras, bem como as atribuições, previstas pelo o Ministério da Educação (Brasil, 2004, p. 41), de fato a organização e ação do conselho requerem muita ação e 
trabalhos de doação dos membros do conselho, que se articulam à função participativa de todos.

Desse modo, "a criação de Instâncias Colegiadas, como o Conselho de Escola, instituídas de forma isolada e burocrática não representam formas significativas de mudanças" (Carozzi, 2015). De acordo com Barroso (2016), a representatividade da comunidade escolar deve ser composta por: diretor da EMEF, professores, outros servidores, pais, alunos e representante da comunidade local. Tendo como objetivo construir uma cultura de participação, tornando a escola "o espaço de aprendizagem política, democrática e de formação político pedagógica, sendo necessária para sua consolidação a busca de articulação entre os processos pedagógicos e a organização da escola" (Barroso, 2016, p. 15).

\section{Método}

Os principais autores que forneceram o suporte metodológico para o desenvolvimento dessa pesquisa qualitativa foram: Gil (2002 e 2008), Oliveira (2002), Bardin (2011), (Pereira A. S. et al., 2018) e Silva \& Menezes, 2005. Contudo, outros autores foram utilizados e devidamente citados e referenciados.

Para esse estudo recorreu-se a pesquisa descritiva (Gil, 2002), com abordagem quali e quanti. A abordagem qualitativa que de acordo com Oliveira (2002, p. 117), possui "a facilidade de poder descrever a complexidade de uma determinada hipótese ou problema, analisar a interação de certas variáveis, compreender e classificar processos dinâmicos experimentados por grupos sociais e apresentar contribuições no processo de mudança [...]”. Em relação aos objetivos, a pesquisa deve ser considerada como exploratória, visando familiarizar-se com o problema identificado, buscando explicitá-lo.

Ademais "realizou-se uma pesquisa qualitativa, do tipo estudo de caso" (Pereira A. S. et al., 2018), com pesquisa de campo. Nesse contexto, quando analisados os procedimentos técnicos, enquadra-se como pesquisa de campo (Gil, 2008). O lócus da pesquisa de campo foi composto por quatro EMEFs de Vitória. Os sujeitos da pesquisa foram os titulares dos Conselhos de Escola de cada escola com a seguinte distribuição por segmento: diretores (4), alunos (3), magistério (4), pais (2), comunidade (3) e servidores (3). As escolas foram codificadas em A, B, C e D, para cada participante adicionou um numeral de 1 (um) a 6 (seis).

A escuta dos titulares dos Conselhos de Escola ocorreu a partir de entrevistas abertas semiestruturadas. Sobre as respostas dos entrevistados foi aplicada a metodologia de análise de conteúdo baseado em Bardin (2011). Com base na proposta dessa autora, a análise foi efetuada em três diferentes polos: pré-análise com o objetivo a sistematização de ideias, a fim de conduzir o desenvolvimento das reflexões; exploração do material, respaldada na modalidade temática, que possibilitou a sistematização dos dados com inferências e unidade de registros relativos ao objetivo formulado; e operações estatísticas simples, conforme a necessidade do estudo. Nesse sentido, foram utilizados quadros e tabela que permitissem visualizar e ampliar as possibilidades de análise e interpretação dos dados.

Já na abordagem quantitativa o objeto de estudo tende a ser quantificável, para que possibilite a sua classificação e posteriormente a sua análise (Silva \& Menezes, 2005). Na parte quantitativa foi desenvolvido um panorama geral das unidades de registro, utilizando a metodologia de Bardin (2011).

\section{Pesquisa de Campo}

A primeira questão sobre o Conselho de Escola trouxe um paralelo sobre o conhecimento dos entrevistados acerca da gestão democrática, a unidade de ensino e o Conselho de Escola, as falas das entrevistas geraram o Quadro 1. 
Quadro 1 - Q1. Como você analisa a gestão dessa Unidade de Ensino entendendo o princípio da gestão democrática com a abrangência e atuação do Conselho de Escola?

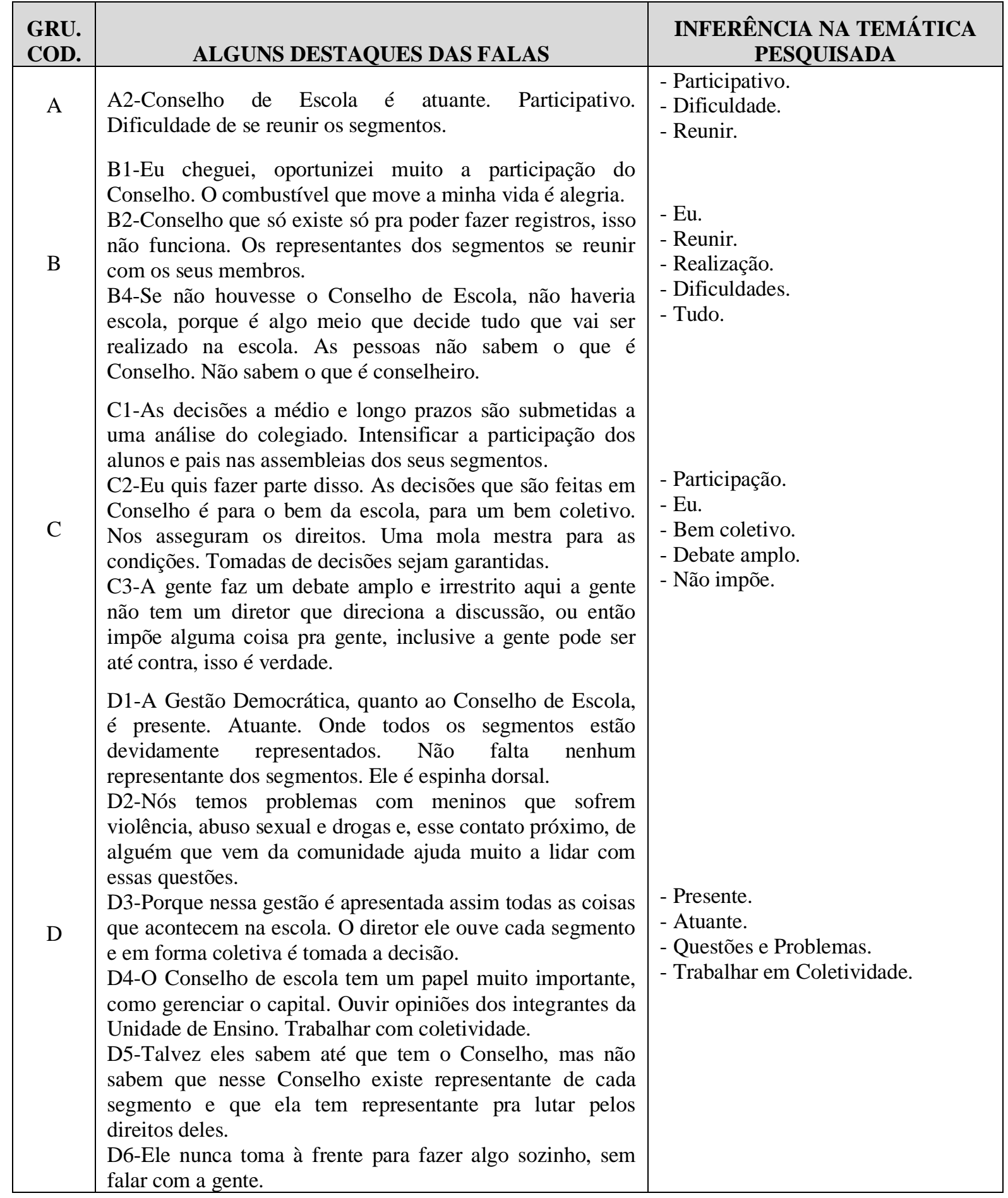

Fonte: Elaborado pela autora a partir dos dados da pesquisa de campo e da concepção de Bardin (2011).

Nota-se que nas falas surgem algumas inferências, tais como: dificuldades, reunir, eu, realização, tudo, debate amplo, não impõe, presente, questões, problemas e trabalhar em coletividade. De modo geral, nas escolas pesquisadas, o Conselho de Escola é visto como um colegiado atuante e participativo. Mas os entrevistados entendem que se reunir enquanto conselho é algo difícil. Entretanto, 'se não houvesse o Conselho de Escola, não haveria escola'. Afinal, esse órgão colegiado é considerado como a 'espinha dorsal' da escola. 
A segunda questão visou identificar os mecanismos que subsidiam a gestão democrática nas EMEFs dos entrevistados. A partir das falas foi elaborado o Quadro 2.

Quadro 2 - Q2. Quais os mecanismos que subsidiam a gestão democrática na escola em que você participa como membro do conselho?

\begin{tabular}{|c|c|c|}
\hline $\begin{array}{l}\text { GRU. } \\
\text { COD. }\end{array}$ & ALGUNS DESTAQUES DAS FALAS & $\begin{array}{c}\text { INFERÊNCIA NA TEMÁTICA } \\
\text { PESQUISADA }\end{array}$ \\
\hline A & $\begin{array}{l}\text { A1-Elaboração de um Projeto Político Pedagógico pela } \\
\text { comunidade escolar. Participação das comunidades no } \\
\text { Conselho de Escola. Escolha do diretor escolar, por eleição. } \\
\text { A2-A participação dos segmentos na elaboração do PPP. A } \\
\text { participação dos segmentos no Conselho de Escola. A } \\
\text { gestão baseada nos princípios de participação da } \\
\text { comunidade escolar e do seu entorno. As eleições diretas. }\end{array}$ & $\begin{array}{l}\text { - PPP. } \\
\text { - Participação. } \\
\text { - Eleições diretas. }\end{array}$ \\
\hline B & $\begin{array}{l}\text { B1-O primeiro mecanismo da participação o envolvimento. } \\
\text { O Conselho de Escola. O envolvimento e a possibilidade de } \\
\text { resgatar o Grêmio Estudantil. Trazer a família para dentro } \\
\text { da escola, mecanismos vivos subsidiando a GD. } \\
\text { B2-O principal ator da gestão democrática dentro da escola } \\
\text { é o diretor, articula todas as ações, principalmente do } \\
\text { Conselho. } \\
\text { B3-A participação de todos. Os pais, alunos, funcionários } \\
\text { precisam opinar para que seja uma gestão bem melhor. } \\
\text { B5-A interlocução. O diálogo. A transparência nas tomadas } \\
\text { de decisões. Participação de todos. O envolvimento e o } \\
\text { comprometimento de toda comunidade escolar, cumprir o } \\
\text { Regimento Interno Escolar. } \\
\text { B6-Um Conselho com participação de todos os segmentos. } \\
\text { A eleição é aberta, qualquer pessoa pode se candidatar, } \\
\text { dentro de cada segmento, já avançamos, movimentos } \\
\text { sociais, via construção da própria sociedade que conseguiu } \\
\text { essas conquistas. }\end{array}$ & $\begin{array}{l}\text { - Participação. } \\
\text { - Conselho de escola. } \\
\text { - Interlocução. } \\
\text { - Diálogo. } \\
\text { - Transparência. } \\
\text { - Comprometimento. } \\
\text { - Comunidade. }\end{array}$ \\
\hline $\mathrm{C}$ & $\begin{array}{l}\text { C1-Participação de todos os segmentos das escolas. Eleição } \\
\text { direta para representantes destes segmentos. Autonomia } \\
\text { financeira. } \\
\text { C2-A escuta sensível. O trabalho em equipe e o } \\
\text { apontamento das necessidades. As vivências [...]. } \\
\text { C3-A Lei de Diretrizes e Bases, a LDB, a de } 1996 \text {. } \\
\text { C4-O Conselho. Quando o diretor toma uma decisão } \\
\text { sozinho, ele pode não agradar a todo mundo. } \\
\text { C5-A parte em que ela junta a comunidade e todos os } \\
\text { outros demais equipamentos pra criar um vínculo de } \\
\text { construção de ideias na execução dos projetos. Um } \\
\text { conjunto do bem servir. Servir mais qualificado. }\end{array}$ & $\begin{array}{l}\text { - Participação. } \\
\text { - Escuta sensível. } \\
\text { - Conselho de escola. } \\
\text { - Aspectos legais. } \\
\text { - Comunidade. } \\
\text { - Decisão. }\end{array}$ \\
\hline $\mathrm{D}$ & $\begin{array}{l}\text { D2-Primeiro é o contato direto. A presença. A comunicação } \\
\text { eficiente. O diálogo sempre. Seriedade. Ética. } \\
\text { Transparência é indispensável. } \\
\text { D3-O diálogo. Momento de escuta. Conhecer também cada } \\
\text { segmento. O pleno desenvolvimento da unidade de ensino. } \\
\text { D4-A escolha do diretor. As opiniões também dadas por } \\
\text { todos. A atitude de cada um de nós. }\end{array}$ & $\begin{array}{l}\text { - Comunicação. } \\
\text { - Diálogo. } \\
\text { - Unidade de ensino. } \\
\text { - Escolha. } \\
\text { - Opiniões. } \\
\text { - Todos. }\end{array}$ \\
\hline
\end{tabular}

Fonte: Elaborado pela autora a partir dos dados da pesquisa de campo e da concepção de Bardin (2011).

A expectativa era de que os entrevistados falassem sobre o Projeto Político Pedagógico, a eleição direta do diretor 
escolar, o Conselho de Escola, dentre outros, mecanismos que subsidiam a Gestão Democrática. Os entrevistados possuíam conhecimento acerca dos mecanismos, trazendo concepções que estão intrinsicamente ligadas aos mecanismos anteriormente citados por Paro (2000), a saber: 'participação', 'escuta sensível', 'contato direto', 'comunicação', 'transparência', 'ética', 'envolvimento', dentre outras falas.

Outra análise produzida a partir das falas dos entrevistados revela as dificuldades e os avanços das EMEFs pesquisadas. Sobre as dificuldades foram analisados os trechos e mostrados o Quadro 3.

Quadro 3 - Dificuldades elencadas e mecanismos inferidos.

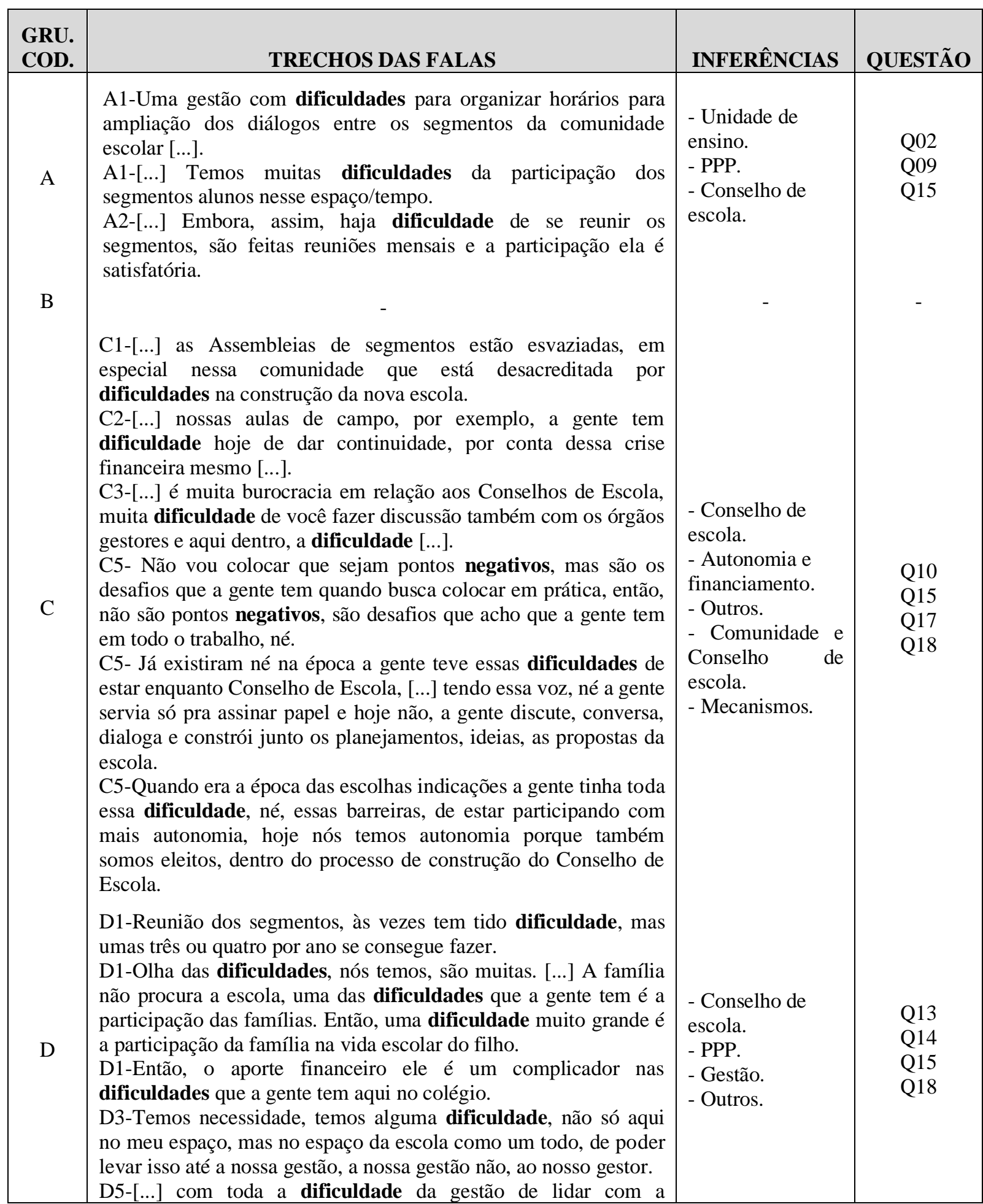


hierarquia [...] Secretários [...] Prefeitos, Vereadores [...].

Fonte: Elaborado pela autora a partir dos dados da pesquisa de campo e da concepção de Bardin (2011).

Destaca-se que ao longo da pesquisa a participação é apontada como uma das condições da Gestão Democrática, entretanto, participar requer dos sujeitos envolvidos espaço e tempo, sendo uma das dificuldades encontradas pelos entrevistados, o que pode de algum modo, comprometer a Gestão Democrática. Entretanto, ressalta-se que a democracia não é algo dado, é conquista, envolvimento e comprometimento.

Outra dificuldade apontada é a ausência ou a pouca frequência da Assembleia por Segmentos. Ressaltando-se que o conselheiro não se auto representa, mas foi eleito para representar o seu segmento. Devendo o conselheiro escutar o seu segmento antes das reuniões ordinárias do Conselho de Escola, para traduzir os anseios, opiniões e sugestões do seu segmento.

Ainda, dentre as dificuldades salientadas, está à insuficiência dos recursos investidos na educação, que prejudica todas as escolas, de um modo geral, mas especialmente àquelas que possuem más condições na infraestrutura física, pois os recursos de custeio são canalizados em reparos para manter minimamente o funcionamento da escola e a manutenção das aulas. Ficando as atividades dos projetos pedagógicos envolvendo o ensino e a aprendizagem, como as aulas de campo, para segundo plano.

Outro questionamento refere-se aos avanços conquistados. A partir dos avanços elencados pelos entrevistados, foi desenvolvido o Quadro 4.

Quadro 4 - Avanços elencados e mecanismos inferidos.

\begin{tabular}{|c|c|c|c|}
\hline $\begin{array}{l}\text { GRU. } \\
\text { COD. }\end{array}$ & TRECHOS DAS FALAS & INFERÊNCIAS & QUESTÃO \\
\hline A & $\begin{array}{l}\text { A2- }[\ldots] \text { foi um avanço muito grande (a escolha do diretor), } \\
\text { principalmente em relação a outros sistemas vizinhos, [...] que } \\
\text { não têm essa modalidade, }[\ldots] \text { Vitória tá um passo à frente, né. }\end{array}$ & $\begin{array}{l}\text { - Eleição direta de } \\
\text { diretor escolar. }\end{array}$ & Q17 \\
\hline B & $\begin{array}{l}\text { B6-[...] é Vitória está bem adiantada no que se refere a isso na } \\
\text { participação dos Conselhos, sabemos também, por exemplo, que } \\
\text { no interior do Estado, existe essa participação de representantes } \\
\text { de todos os segmentos, mas muitos são cooptados e não têm tanta } \\
\text { voz, espaço, quanto eu acho como Vitória já conquistamos, já } \\
\text { avançamos, aí eu acho que avanço vem da Prefeitura, mas vem } \\
\text { dos movimentos sociais, via construção da própria sociedade que } \\
\text { conseguiu essas conquistas. }\end{array}$ & $\begin{array}{l}\text { - Gestão } \\
\text { democrática. }\end{array}$ & Q11 \\
\hline C & $\begin{array}{l}\text { C5-[...] há anos atrás, a gente tinha toda essa barreira, }[\ldots] \text { do } \\
\text { Conselho de Escola, ele existia simplesmente porque era } \\
\text { necessário. Hoje o CE ele existe, tem voz e tem vez, né então } \\
\text { isso tudo foi tudo um processo de construção. }\end{array}$ & $\begin{array}{l}\text { - Conselho de } \\
\text { Escola. }\end{array}$ & Q16 \\
\hline D & $\begin{array}{l}\text { D2-É [...] De repente, você não tem uma demanda de Custeio, } \\
\text { mas tem a verba, você não pode usar na de Capital. Isto te limita, } \\
\text { né. Mas com relação à autonomia, dentro da possibilidade do que } \\
\text { permite a verba o [...] consegue grandes avanços. } \\
\text { D5-Eu acho que o avanço é justamente essa garantia de direitos } \\
\text { mesmo. }\end{array}$ & $\begin{array}{l}\text { - Autonomia e } \\
\text { financiamento; } \\
\text { - Outros. }\end{array}$ & $\begin{array}{l}\text { Q10 } \\
\text { Q18 }\end{array}$ \\
\hline
\end{tabular}

Fonte: Elaborado pela autora a partir dos dados da pesquisa de campo e da concepção de Bardin (2011).

No que tange a temática da pesquisa, o Conselho de Escola, diversas foram as falas que envolveram os avanços, entre elas: a eleição direta de diretor escolar, a Gestão Democrática, o Conselho de Escola, a autonomia e o financiamento, foram 
retratados nos trechos das falas. Vale destacar que poucos são os avanços conquistados pela rede municipal de ensino de Vitória, ou pelo menos, percebidos pelos participantes.

Analisando as entrevistas na íntegra foi desenvolvido um panorama geral das unidades de registro, utilizando a metodologia de Bardin (2011), contemplando-as na ordem crescente quanto à frequência que aparecem na integralidade das falas dos entrevistados, e os seus respectivos percentuais conforme a Tabela 1.

Tabela 1 - Frequência das unidades de registro.

\begin{tabular}{c|l|r|r}
\hline $\mathbf{R}$ & \multicolumn{1}{|c|}{ UNIDADES DE REGISTRO } & FR & \multicolumn{1}{c}{$\%$} \\
\hline 1 & Conselho/CE & 265 & 16,55 \\
2 & Participar & 204 & 12,74 \\
3 & Gestão/GD & 178 & 11,12 \\
4 & Segmento & 165 & 10,31 \\
5 & Diálogo/Falar/Ouvir/Escuta & 148 & 9,24 \\
6 & Representar (variáveis) & 91 & 5,68 \\
7 & Trabalhar & 91 & 5,68 \\
8 & Escolher/decisão & 76 & 4,75 \\
9 & Recursos Financeiros/dinheiro/financiamento/verba & 61 & 3,81 \\
10 & Falta de Tempo & 48 & 3,00 \\
11 & Família & 41 & 2,56 \\
12 & Autonomia & 37 & 2,31 \\
13 & Pedagógico & 34 & 2,12 \\
14 & Valorizar & 34 & 2,12 \\
15 & Organização & 33 & 2,06 \\
16 & Recursos & 29 & 1,81 \\
17 & Dificuldade & 27 & 1,69 \\
18 & Formação & 21 & 1,31 \\
19 & Democrática/Democrático & 18 & 1,12 \\
\hline & & $\mathbf{1 6 0 1}$ & $\mathbf{1 0 0 , 0 0}$ \\
\hline
\end{tabular}

Fonte: Elaborado pela autora a partir dos dados da pesquisa de campo e da concepção de Bardin (2011).

Ao analisar o quadro geral das unidades de registros, obtido a partir da frequência apresentada pelas respostas originais de todos os entrevistados, observa-se a relação direta de 1-Conselho, 2-Participar e 3-Gestão Democrática, totalizando o percentual de $40,41 \%$ das frequências. De modo que é possível interpretar que o mecanismo que mais representa a Gestão Democrática nas unidades de ensino pesquisadas é o Conselho de Escola, que só se estabelece com a participação efetiva dos conselheiros e dos demais membros da comunidade escolar e local. De fato, o Conselho de Escola é o órgão colegiado que deve gerir a escola, sendo ele, inclusive, responsável por afastar ou destituir o diretor, nos casos específicos da lei.

As unidades de registros 4-Segmento, 5-Diálogo/Falar/Ouvir/Escuta e 6-Representar, também possuem uma ligação direta entre si, e se relacionam com as anteriores. Ou seja, o Conselho de Escola se constitui a partir da participação dos segmentos, caracterizando-se como órgão colegiado, com a finalidade de buscar uma gestão em que todos possam dela participar e/ou sentir-se ali representados. A mola propulsora que envolve a Gestão Democrática está na unidade de registro 5, portanto, o exercício da Gestão Democrática pressupõe o diálogo; o direito e o respeito às falas dos sujeitos que utilizam o serviço público educacional; enquanto a escuta é um exercício necessário que precisa existir ou ser aprendido para que possa haver a democracia. Juntas essas três unidades de registros totalizam 25,23\% da frequência.

$\mathrm{Na}$ sequência, as unidades de registro 7-Trabalhar, 8-Escolher/decisão e 9-Recursos 
Financeiros/dinheiro/financiamento/verba, remetem às atribuições que envolvem o Conselho de Escola. Esse órgão colegiado tem a incumbência e a atribuição de administrar os recursos provenientes tanto das fontes municipais, quanto os recursos das fontes federais. Outra interpretação que também pode ser feita é o quanto os Conselhos de Escola têm se imbuído dessa atribuição, de modo que, a atividade fim da escola que envolve o processo de aprender e ensinar, pode ser deixada no plano secundário das discussões desse órgão colegiado. O total dessas frequências atinge o percentual de 14,24\%.

Outras duas unidades de registro que serão destacadas são a 15 -valorização, com a frequência de $2,12 \%$ e a 18 formação com 1,31\%. Essas duas unidades remetem-nos tanto à valorização da participação e dos mecanismos da Gestão Democrática, que o município de Vitória já conquistou em relação às outras redes, quanto à necessidade de valorização da educação pública por parte do poder executivo; incluindo também os servidores públicos municipais, que hoje passam pelo achatamento de seus salários. Quanto à formação, defende-se que ela também é uma forma de valorização. É preciso, portanto, envolver a formação dos trabalhadores e dos conselheiros na perspectiva da educação pública municipal, que se quer democrática e de qualidade.

\section{Considerações Finais}

Esse artigo teve como objetivo analisar um dos mecanismos da Gestão Democrática - o Conselho de Escola, sob a percepção desse órgão colegiado. No arcabouço teórico dessa pesquisa, que corresponde à pesquisa bibliográfica, fica claro que uma das formas de fortalecer a gestão democrática é promover a participação da comunidade escolar e da comunidade local e que, o principal mecanismo é o conselho de escola.

$\mathrm{Na}$ abordagem prática, principalmente baseada na metodologia de Bardin (2011), nos aspectos qualitativos foram organizados quadros com alguns destaques das falas dos entrevistados. Foram identificadas algumas inferências sobre a temática pesquisada.

A partir da estatística simples, quando observadas as falas dos entrevistados, verifica-se nas respostas, uma frequência de 265, correspondendo a $16 \%$ das unidades de registros, referente ao Conselho de Escola. Destacam-se outras unidades de registros que colaboram na percepção sobre a busca da gestão democrática, essas unidades de registros são descritas com suas respectivas frequências e porcentagens: participar (fr 204 e 12,74\%), gestão/gestão democrática (fr 178 e 11,12\%), segmento (fr 165 e 10,31\%) e diálogo/falar/ouvir/escuta (fr 148 e 9,24\%).

Vale mencionar que tanto nas unidades de registros na análise qualitativa, quanto na estatística simples, as inferências dialogam e se relacionam com o referencial teórico.

Em resposta ao problema que orientou essa pesquisa - Qual é o papel do Conselho de Escola na Gestão Democrática na percepção do órgão colegiado?

O conselho de escola foi caracterizado como a 'espinha dorsal' da escola que pretende administrar dentro do contexto da gestão democrática;

$\mathrm{Na}$ maioria das escolas pesquisadas o conselho de escola é visto como atuante, com voz ativa e conselheiros participativos.

Nesse contexto, foram citadas as dificuldades da participação da comunidade escolar e local na gestão colegiada. Entre as dificuldades apresentadas estão: dificuldade em organizar os horários, falta de investimento, a burocracia excessiva em relação aos conselhos de escola, as ausências das Assembleias por Segmentos.

Ao considerar a pesquisa de uma maneira mais holística, ressalta-se que ainda existe muito para ser explorado sobre a temática. Assim, diante disso, são desenvolvidas as seguintes recomendações para trabalhos futuros:

Estudos que apontem os impactos das Assembleias por Segmentos (pais, alunos, magistério e demais servidores) na gestão colegiada; 
Trabalhos de pesquisa que relacionem os órgãos colegiados e a manutenção dos respectivos períodos de reuniões do conselho de escola;

Investigação sobre a utilização das mídias digitais existentes na comunidade escolar e local para fortalecer a participação e os canais de comunicação dando transparência das informações: blogs, grupos de WhatsApp, correio eletrônico, dentre outros;

Estudos que pesquisem sobre a efetividade das formações continuada e o impacto dessas formações sobre a melhoria da participação na gestão colegiada.

Como contribuição, espera-se que este trabalho possa nortear novos trabalhos de pesquisa sobre o princípio da gestão democrática e seus mecanismos. Além disso, espera-se que essa pesquisa sirva de impulso para que os entrevistados possam cada vez mais vivenciar a escola como um ambiente de participação.

\section{Referências}

Bardin, L. (2011). Análise de conteúdo. São Paulo: Edições 70.

Barroso, D. T.A. (2016). O conselho escolar e os desafios da participação e da autonomia na escola pública. $91 \mathrm{f}$. Dissertação de Mestrado (Mestrado em Educação) Programa de Pós-Graduação Profissional em Educação, Universidade de Pernambuco Mata Norte, UPE, Brasil.

Brasil. (1988). Constituição da República Federativa do Brasil de 1988. Brasília: Senado Federal.

Brasil - MEC. (2004). Conselho Escolar, democratização da escola e construção da cidadania. Caderno 1. Brasília: [s.n.]. http://portal.mec.gov.br/seb/arquivos/pdf/Consescol/ce_cad1.pdf.

Brasil - MEC. (2004) Conselho Escolar, gestão democrática da educação e escolha do diretor. Caderno 5. Brasília: [s.n].http://portal.mec.gov.br/seb/arquivos/pdf/Consescol/ce_cad5.pdf>.

Brasil - Senado Federal. 1996. Lei de Diretrizes e Bases da Educação Nacional: nº 9.394/96. Brasília. Recuperado de: http://www2.camara.leg.br/.

Caregnato, R. C. A., \& Mutti, R. (2006). Pesquisa qualitativa: análise de discurso versus análise de conteúdo. Texto \& Contexto Enfermagem, 15 (4), 679-684. doi:10.1590/S0104-07072006000400017.

Carozzi, E. S. (2015) Organização e Gestão Escolar: uma análise do conselho escolar na rede municipal de Cascavel. 190f. Dissertação de Mestrado (Mestrado em Educação) Programa de Pós-Graduação em Educação, Universidade Estadual do Oeste do Paraná, UNIOESTE, Brasil.

Castro, M. L. S. de. (2016). Conselho escolar: a busca pela solução de entraves no funcionamento do trabalho pedagógico. 86f. Dissertação de Mestrado (Mestrado profissional em gestão e avaliação da educação pública) - Universidade Federal de Juiz de Fora, Centro de Políticas Públicas e Avaliação da Educação, Programa de pós-graduação profissional em Gestão e Avaliação da Educação Pública, Juiz de Fora, MG.

Delgado, G. de O. (2015). Conselhos escolares e gestão democrática do ensino público: análise da implementação e do papel do conselho escolar em uma escola técnica estadual de ensino médio em Campos dos Goytacazes/RJ. 104 f. Dissertação (mestrado em educação) - Universidade Estadual do Norte Fluminense Darcy Ribeiro - UENF, Centro de Ciências do Homem - CCH, Programa de Pós-Graduação Em Políticas Sociais - PPGPS, Campos dos Goytacazes, RJ.

Gil, A. C. (2008). Métodos e técnicas de pesquisa social. São Paulo: Atlas.

Gil, A. C. (2020) Como elaborar projetos de pesquisa. 4ed. São Paulo: Atlas.

Oliveira, S. L. de. (2002). Tratado de Metodologia Científica: projetos de pesquisas, TGI, TCC, monografia, dissertações e teses. 2 ed. São Paulo: Pioneira Thomson.

Pereira A. S. et al. (2018). Metodologia da pesquisa científica. [e-book]. Santa Maria. Ed. UAB/NTE/UFSM. https://repositorio.ufsm.br/bitstream/handle/1/15824/Lic_Computacao_Metodologia-Pesquisa-Cientifica.pdf?sequence=1.

Paro, V. H. (2000). Por dentro da escola pública. 3 ed. São Paulo: Xamã.

Paro, V. H. (1995). Por dentro da escola pública. São Paulo: Xamã.

Qedu. (2015). Vitória: IDEB 2015 por escolas. 2017. http://www.qedu.org.br/cidade/2731-vitoria/ideb/ideb-por-escolas.

Ramos, G. P., \& Fernandes, M. C. (2010). Lutas, contradições e conflitos: a construção histórica do conselho escolar no Brasil. In: Luiz, M. C. (org.). Conselho escolar: algumas concepções e propostas de ação. São Paulo: Xamã

Riscal, S. A. (2010). Considerações sobre o conselho escolar e seu papel mediador e conciliador. In: Luiz, M. C. (org.). Conselho escolar: algumas concepções e propostas de ação. São Paulo: Xamã.

Rodrigues, N. (1987). Da mistificação da escola à escola necessária. São Paulo: Cortez, 1987. 
Research, Society and Development, v.10, n.1, e3610111420, 2021 (CC BY 4.0) | ISSN 2525-3409 | DOI: http://dx.doi.org/10.33448/rsd-v10i1.11420

Silva, E. L., \& Menezes, E. M. (2005). Metodologia da pesquisa e elaboração de dissertação. 4ed. Florianópolis. Universidade Federal de Santa Catarina.

Sousa, S. Q. (2016). Análise da atuação do conselho escolar em uma escola da rede municipal de Manaus. 138f. Dissertação de Mestrado (Mestrado profissional em gestão e avaliação da educação pública) - Universidade Federal de Juiz de Fora, Centro de Políticas Públicas e Avaliação da Educação, Programa de pós-graduação profissional em Gestão e Avaliação da Educação Pública, Juiz de Fora, MG.

Vitória. (2006). Lei orgânica municipal no 6.794, 29 de novembro de 2006. Vitória. 